\title{
Using Business Process Re-engineering to Increase Process Efficiency of E-Catalogue Distribution System
}

\author{
Zulkhairi Md Dahalin and Siti Fatimah Yusof \\ Universiti Utara Malaysia, Kedah, Malaysia
}

\begin{abstract}
The traditional printed paper based product catalogue is restricted to customers and places, which is difficult to handle in addition to time and cost of printing, storage area and shipping. Thus, this study attempts to present the results of a business process re-engineering of a direct selling catalogue distribution that is able to eliminate such physical limitations and enable the distribution business process to become more efficient. Incorporating e-catalogue as an outcome of the business process re-engineering shows that the business process can be simplified from 32 activities to 13 activities. With this approach the percentage of process efficiency rate for business process selected has been increased dramatically from $20 \%$ up to $86 \%$ and also reduced the waiting rate from $55 \%$ to $7 \%$. In order to rate the usefulness of the e-catalogue solution, 30 respondents from direct selling dealers were selected to test the e-catalogue prototype. The final result indicates that business process re-engineering has the capability to simplify a fairly complex manual and paper-based processes, resulting in a better, more efficient e-catalogue distribution system.
\end{abstract}

Keywords: BPR, efficiency, direct selling.

\section{Introduction}

The significant growth of the internet usage for advertising and selling of products has become dramatic in recent years, particularly with the proliferation of broadband technology. According to ITU (2010), which is a leading agency for information and technology issues, about $64.4 \%$ from $26,160,256$ of the Malaysian population are using the internet. In fact, the number of internet subscribers expected to reach 10 million in the next five years (Telekom Malaysia, 2007). Considering this volume of data, today many people make use of the internet in working, learning and sales on line with greater speed and accuracy regardless of time and distance.
In 2008, internet sales for the United Kingdom increased by $51 \%$ relatively from 2007 to 2008 (Statistical Bulletin, 2009). This number indicates that users preferred to buy and sell online rather than traditional retail shopping. Technically, online business is associated with 4 components, which are product catalogue, Shopping Cart, Transaction Security and processing order. Combination of these elements can provide a true shopping experience to the customer (Greenberg, 2001).

With the influx of businesses conducted online taking advantage of the internet technology, the use of e-catalogue rather than printed version product catalogue has become a viable alternative. The potential to

Copyright (C) 2012 Zulkhairi Md Dahalin and Siti Fatimah Yusof. This is an open access article distributed under the Creative Commons Attribution License unported 3.0, which permits unrestricted use, distribution, and reproduction in any medium, provided that original work is properly cited. Contact author: Zulkhairi Md Dahalin E-mail: zul@uum.edu.my 
reach a larger market based on online catalogue which is more dynamic, flexible and consumer responsive has been identified by researchers (Vijayasarathy \& Jones, 2000). Other researchers such as Kotler (2000) and Muldoon (1996) also predicted that online catalogue will become more popular than traditional print catalogue due to quicker access, price comparison and faster searching capability.

Although the internet offers many potential benefits, direct selling companies still distribute this traditional print catalogue among their dealers nationwide through manual distribution process. Basically, these companies used printed version product catalogue in order to sell their products. With the rapidly high cost distribution and printing, a study by Rosman (2010) identifies approximately RM800,000 monthly was needed to spend on printing and distribution process. This triggered the interest to further examine what is the most suitable application to be applied in order to solve this issue and how Business Process Reengineering technique can improve efficiency and effectiveness of the company performance.

\section{Background of the Study}

A direct selling company, which was used in this study, established since 1978 in Malaysia has empowered many women across the Peninsular, including Sabah and Sarawak by providing them with earning opportunities and making their dreams come true. The company's representatives are supported by their zone manager, training, credit facilities and numerous Beauty Boutiques around Malaysia. The location of the company's headquarters is based in Petaling Jaya, Selangor.
This company has its own vision which is to be the company that best understands and satisfies the products, services and selffulfillment needs of women globally. The company has multiple missions in their organization which, among others, are listed as follows:

i. To become the world's most trusted beauty company

ii. To create lifelong customer relationship

iii. To achieve economic independency

iv. To become the largest woman's foundation

v. To create exceptional opportunities for professional growth

vi. To be a socially responsible, ethical company that is watched and emulated as a model of success

The company developed their own website which is limited to basic information about company profile, account numbers for dealers and short news about current programs. Although the company has their own web site, the company used manual process to distribute their product catalogue to all dealers and Beauty Boutiques around Malaysia.

For the purpose of this study, the process selected for reengineering is the product catalogue distribution process. The complete existing process is presented in a flowchart as illustrated in Fig 1. The description of the existing and reengineering processes for the product catalogue distribution is presented in the next sections. 


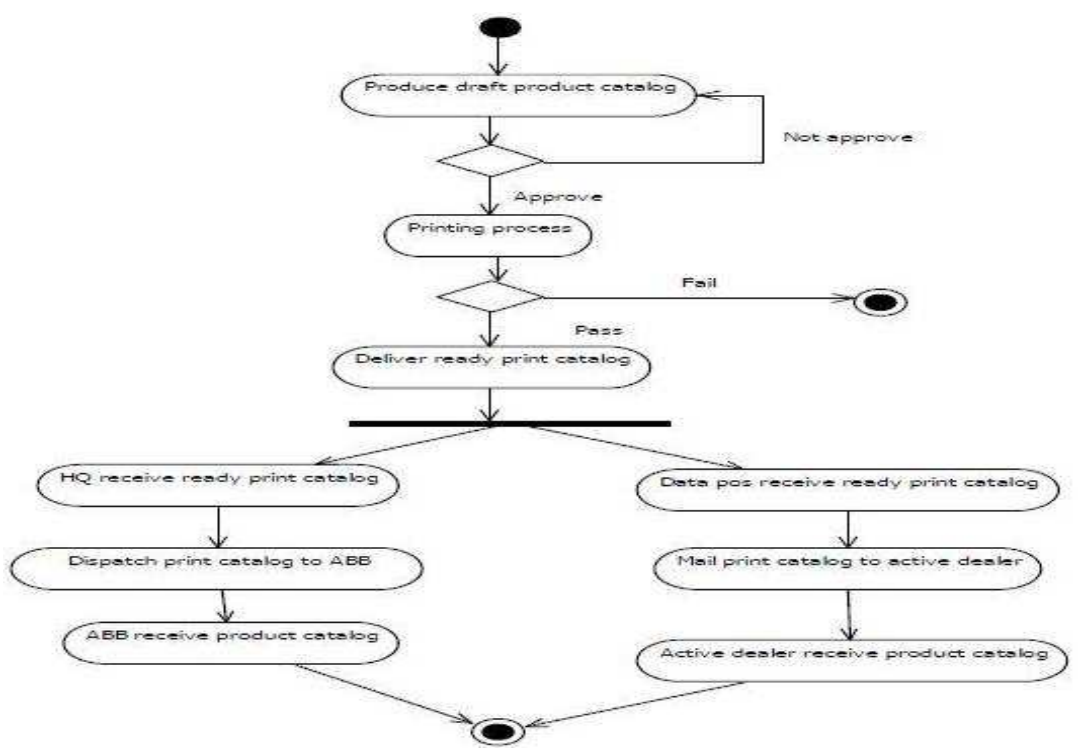

Fig 1. Flowchart of Product Catalogue Distribution Process

\section{Description of Existing Process}

The existing business process for the product catalogue distribution process can be summarized as follows:

i. The process begins with Art Director to produce a draft of the catalogue.

ii. The Art Director presents draft to Marketing Manager and Senior Art Director in order to get the approval. If the draft is not approved then it will get back to Art Director for amendment, if the draft is approved and finalized, the work design details and proceeds to printing process.

iii. The Marketing Manager will check whether the printing process is successful. If the printing is not successful then the process will end. If the printing process is successful then the ready print catalogue will be delivered to $\mathrm{HQ}$ and Data Pos.

iv. From HQ, the bundle of print product catalogue will be dispatched to Beauty Boutiques nationwide. v. From Data Pos, the print product catalogue will be mailed to all active dealers.

Beauty Boutiques and active dealers receive the product catalogue and the process ends.

Based on the analysis of the existing business process, there are seven main activities involved. These are:

i. Produce draft product catalogue

ii. Request for printing product catalogue

iii. Update record for top sellers and active/ inactive dealers

iv. Deliver ready print product catalogue

v. Data Pos receive ready print product catalogue

vi. Active dealer receive Product catalogue

vii.Beauty Boutiques receive Product catalogue 
From the main activities, there are subactivities that should be completed which take time to complete for every stage (See
APPENDIX B). People (actors) involved in the work process are as follows:

\begin{tabular}{|ll|ll|}
\hline i. & Marketing Manager & vii. & Supervisor \\
ii. & Marketing Assistant Manager & viii. & Warehouse Assistance \\
iii. & Senior Art Director & ix. & Account Maintenance Officer \\
iv. & Art Director & x. & Sales Representatives \\
v. & Copywriter & xi. & Dealers \\
vi. & Supply Chain Manager & xii. & Data Pos \\
& & & \\
\hline
\end{tabular}

The total time taken for the whole work processes to complete was 46,186 minutes. This can be shown in the following calculation to identify the value for process efficiency rate and waiting rate:

\section{Calculation of Existing Process}

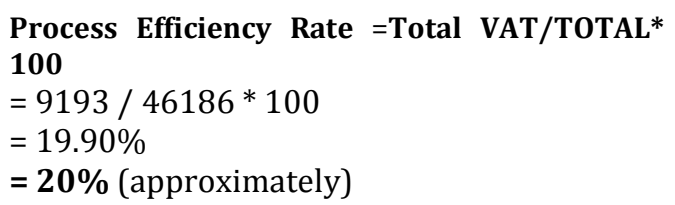

Based on the calculation of the existing process, the percentage of Process Efficiency Rate is $20 \%$, whereas the Waiting Rate is $55 \%$. Clearly, the existing process is inefficient and wastes a lot of time as more than half of the time for the process to complete is to wait for the subsequent activity in the process. The BPR technique was used to identify the time consuming activities and introduce ICT to automate the business process.

A Pareto chart (see APPENDIX C) was used to determine and compare significant timeconsuming activities that are potential for reengineering. Basically, this is a bar graph that shows all the activities involved and sorted in descending time order. The longest time taken for each activity will be arranged at the left most position, whereas those activities with the shortest time will be shifted to the right-most position. According to Pareto principle, a 20/80 percent rule was applied to identify the $20 \%$ significant activities that contribute to $80 \%$ of the time to accomplish the selected business process. The 20\% activities generated by the Pareto chart identified the following activities: Keep the print catalogue; Receive the bundle of new print catalogue; Coordinate the printing job; and Distribute print product catalogue that consumed most of the time.

\section{Description of Re-Engineering Process}

The idea in this re-engineering process is to make use of the company website to allow every dealer, whether active or not, to view the e-catalogue online. The steps of the process are shown in APPENDICES D and E.

This can be done by introducing a new reengineer process using the e-catalogue as an online application. With this application, the activities in the work process can be reduced and at the same time it will help to increase the process efficiency rate of the work process.

After the e-catalogue is received from the Marketing Assistance Manager, the Copywriter will upload the e-catalogue to the company web site. Then, dealers, Beauty Boutiques and customers can access the company web site and click on 'E-catalogue'.

Based on the analysis of the online of the work process schedule, there are three main activities involved. These are: 
i. Produce draft product catalogue

ii. Receive e-catalogue

iii. View e-catalogue

From the main activities, there are subactivities that should be completed which take time to complete for every stage. The people involved in the work process are: the Marketing Manager, the Marketing Assistant Manager, Senior Art Director, Art Director, Copywriter, Sales Representatives, Dealers, and Customer.

For the re-engineered process, the total time taken for the whole work processes to complete was 9,281 minutes. This can be shown in the following calculation to identify the value of process efficiency rate and waiting rate for the new work process:

\section{Calculation of Re-engineering Process}

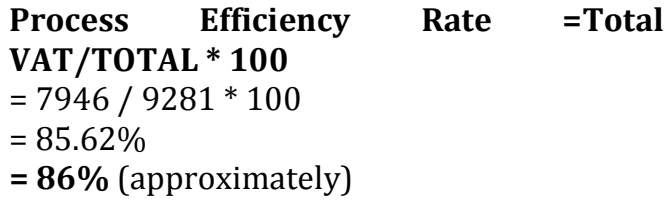

The results show that product catalogue distribution process through online application helps to increase the efficiency rate from $20 \%$ to $86 \%$. It also shows that the number of waiting time was reduced from $55 \%$ to $7 \%$. Therefore, it can be concluded that the proposed e-catalogue incorporating in Business Process Re-engineering technique in this study can contribute to increase process efficiency and provide significant time saving.

\section{Discussion}

According to the original work process mapping, 32 activities were needed to accomplish all seven main activities as discussed earlier. From the current analysis (APPENDIX A), the total time to complete the whole process is 46,186 minutes. With the BPR technique, the 32 activities can now be reduced to merely 13 activities, a reduction of almost $60 \%$ less activities. The use of ecatalogue allows all dealers to view the catalogue information and latest updates on products within an instance. For the organization, the cost for delivery and printing process can be eliminated. The total time taken to complete the process is reduced to 9,281 minutes compared to 46,186 minutes previously. This indicates that the process after BPR is more efficient compared to existing process where the efficiency rate is up to $86 \%$. Another impact is the waiting time can now be dramatically reduced from $55 \%$ to $7 \%$.

\section{Conclusion}

In conclusion, adopting the BPR approach could be considered practical, reliable and useful to increase business including manager, employees, dealers and customers, in helping organizations to increase their business performance. The significant result of the business process efficiency shows that the product catalogue distribution process can be simplified by implementing ecatalogue using the BPR approach. There are no more delays, everyone can receive ecatalogue at the appropriate time and also organizations can ultimately reduce the cost for delivery and printing. Finally, in return, all users involved in this process will be able to achieve satisfaction.

\section{References}

Greenberg, P. A. (2001). 'In E-Commerce We Trust ... Not,' [Online],[Retrieved October 15, 2010],

http://WWW.ecommercetimes.com/perl/sto ry/?id=7194

Hammer, M. \& Champy, J. (1993). "Reengineering the Corporation, a Manifesto for Business Revolution," New York: Harper Collins. 
ITU (2010). "Malaysia Internet Usage Stats and Marketing Report," [Online],[Retrieved October 25, 2010], http://www.internetworldstats.com/asia/m y.htm

Kotler, P. (2000). 'Marketing Management,' Prentice-Hall: Englewood Cliffs, New Jersey.

MAMPU. (2009). 'Manual Perekayasaan Proses Dan Prosedur Kerja Bagi Sector Awam,' Putrajaya: Malaysia Government Printing Office.

Muldoon, K. (1995). How to Profit Through Catalogue Marketing (NTC Business Books) Lincolnwood, IL.
Statistical Bulletin. (2009). "E-commerce and Information and Communication Technology (ICT) activity," 2008, [Online], [Retrieved October 25, 2010], http://www.internetworldstats.com/asia/m y.htm

Telekom Malaysia (2007). "Malaysia Internet Subscribers to Double by 2012,"[Online],[Retrieved October 25, 2010], http://www.internetworldstats.com/asia/m y.htm

Vijayasarathy, L. R. \& Jones, J. M. (2000). "Print and Internet Catalogue Shopping: Assessing Attitudes and Intentions," Internet Research, 10(3), 191-202. 
7 IBIMA Business Review

Appendix A : Work Process Schedule for Existing Product Catalogue Distribution Process

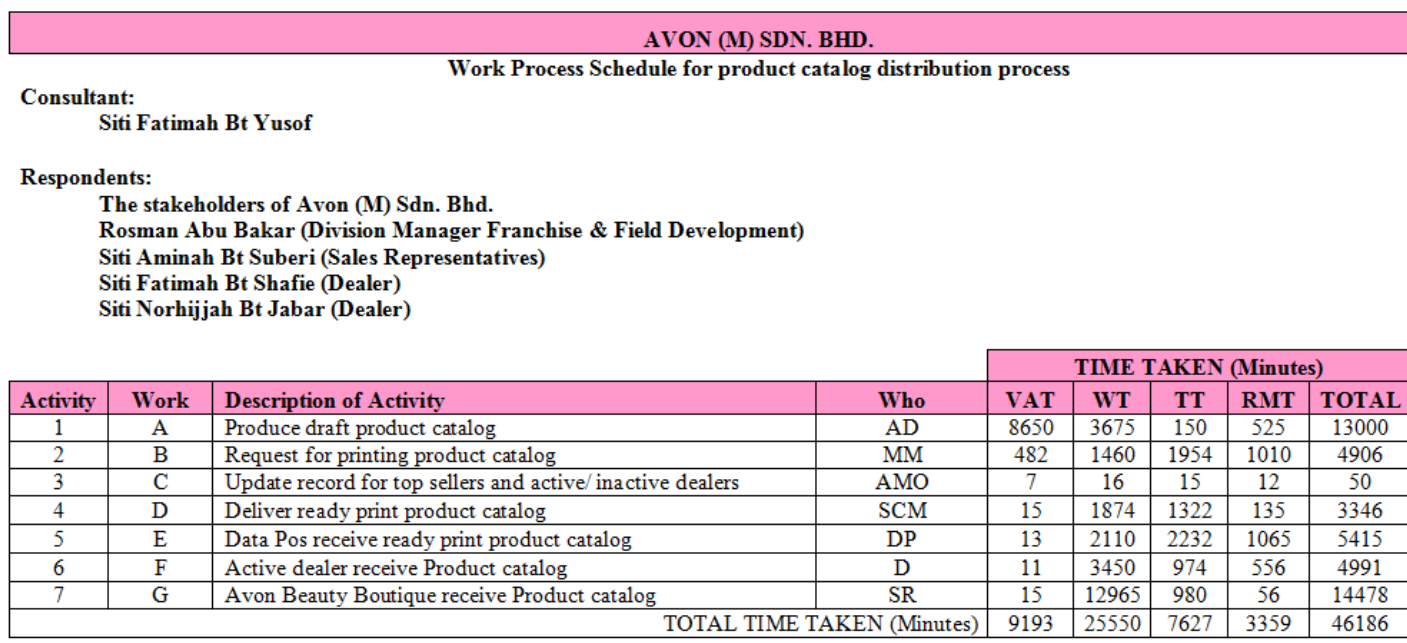

Appendix B: Work Process Mapping for Existing Product Catalogue Distribution Process

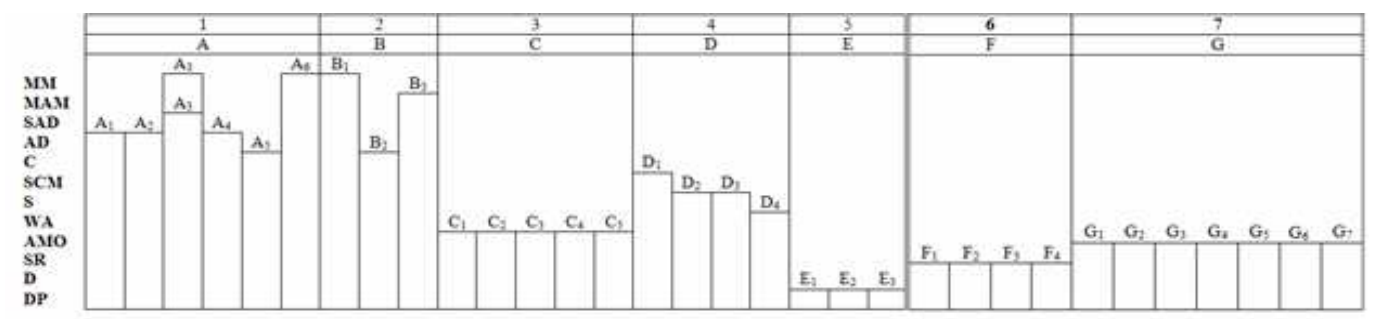

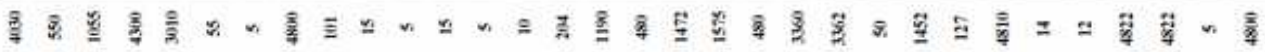

Time taken (minutes) 
Appendix C Pareto Chart

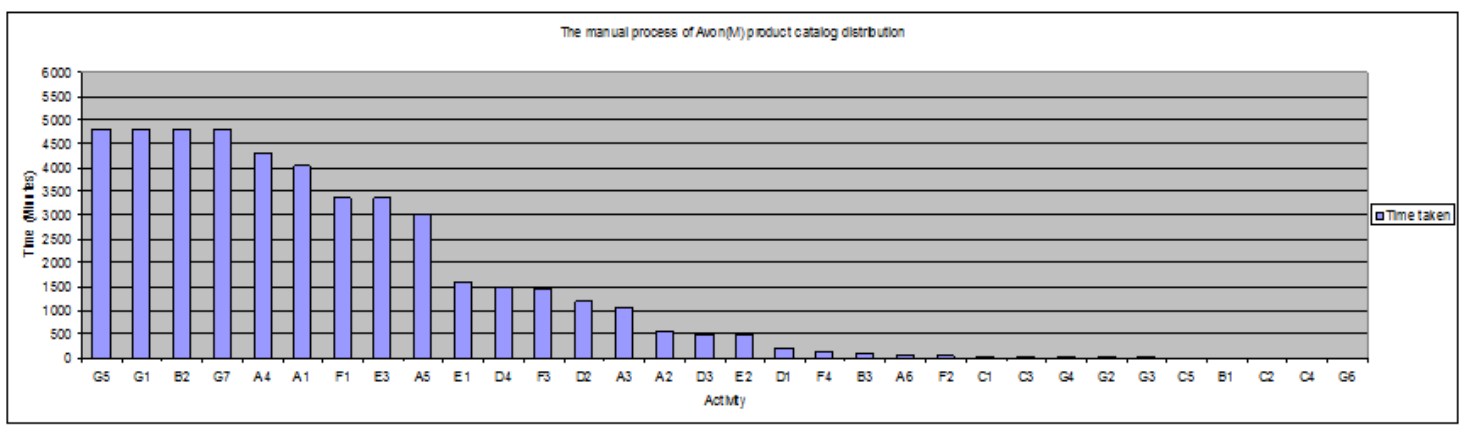

Appendix D: Work Process Schedule for the Re-engineered Product Catalogue Distribution Process

AVON (M) SDN. BHD.

\begin{tabular}{|c|c|c|c|c|c|c|c|c|}
\hline \multicolumn{9}{|c|}{ AVON (M) SDN. BHD. } \\
\hline \multicolumn{9}{|c|}{ Work Process Schedule for product catalog distribution process } \\
\hline \multicolumn{9}{|c|}{$\begin{array}{l}\text { Respondents: } \\
\text { The stakeholders of Avon (M) Sdn. Bhd. } \\
\text { Rosman Abu Bakar (Division Manager Franchise \& Field Development) } \\
\text { Siti Aminah Bt Suberi (Sales Representatives) } \\
\text { Siti Fatimah Bt Shafie (Dealer) } \\
\text { Siti Norhijjah Bt Jabar (Dealer) }\end{array}$} \\
\hline & & & & & & & DUT & TOTAT \\
\hline Activity & Work & Description of Activity & Who & VAT & WT & TT & 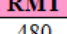 & TOTAL \\
\hline$\frac{1}{2}$ & $\begin{array}{l}\mathrm{A} \\
\mathrm{B}\end{array}$ & $\begin{array}{l}\text { Produce draft product catalog } \\
\text { Receive e-catalog (ready files) }\end{array}$ & $\frac{\mathrm{AD}}{\mathrm{MAM}}$ & $\begin{array}{c}7765 \\
16\end{array}$ & $\frac{625}{15}$ & \begin{tabular}{c|c}
125 \\
15
\end{tabular} & $\frac{480}{-}$ & 8995 \\
\hline 3 & $\mathrm{C}$ & View e-catalog & $\mathrm{C} / \mathrm{D} / \mathrm{SR}$ & 165 & 27 & 23 & 25 & 240 \\
\hline \multicolumn{4}{|c|}{ TOTAL TIME TAKEN (Minutes) } & 7946 & 667 & 163 & 505 & 9281 \\
\hline
\end{tabular}

Appendix E: Work Process Mapping for Existing Product Catalogue Distribution Process

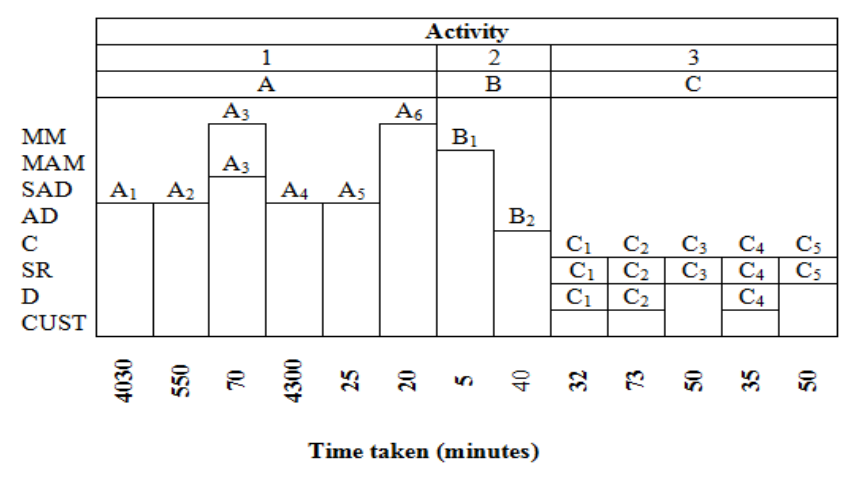

